\title{
Crescimento in vitro e aclimatização de Cattleya loddigesii Lindley (Orchidaceae) com carvão ativado sob dois espectros luminosos
}

\author{
In vitro growth and acclimatization of Cattleya loddigesii Lindley (Orchidaceae) with actived \\ charcoal in two light spectra
}

\author{
Renato Fernandes Galdiano Júnior, Cibele Mantovani ${ }^{\mathrm{II}}$ Kathia Fernandes Lopes Pivetta ${ }^{\mathrm{II}}$ \\ Eliana Gertrudes de Macedo Lemos ${ }^{\mathrm{IV}}$
}

\section{RESUMO}

O objetivo deste estudo foi avaliar a adição de concentrações de carvão ativado em meio de cultura $1 / 2 \mathrm{MS}$ (com metade da concentração dos macronutrientes) sob dois espectros luminosos para a obtenção de plântulas in vitro de Cattleya loddigesii. Plântulas com aproximadamente 90 dias foram subcultivadas em oito tratamentos, nos quais foi testada a adição ao meio de cultura $1 / 2 \mathrm{MS}$ com carvão ativado (0; 0,5; 1,0 e 2,0g $\mathrm{L}^{-1}$ ) e combinados sob espectro de luz branca e luz vermelha. Após 180 dias da germinação, foram mensurados dados biométricos (raiz e parte aérea), massa fresca e teores de pigmentos fotossintéticos. Em plântulas aclimatizadas em casa de vegetação, foram avaliadas a taxa de sobrevivência após 120 dias. As concentrações de clorofila total, clorofila a e carotenoides foram maiores nos tratamentos sob luz branca, enquanto a luz vermelha influenciou significativamente maior clorofila $b$, plântulas com menos raízes e de menor comprimento e elevada mortalidade ex vitro. A adição de $2,0 \mathrm{~g} \mathrm{~L}^{-1}$ de carvão ativado ao meio de cultura e o uso de luz branca proporcionaram maior eficiência de desenvolvimento tanto para as culturas in vitro quanto para a sobrevivência ex vitro das plantas.

Palavras-chave: germinação in vitro, luminosidade, tipo de luz, orquídea, plântulas e sobrevivência ex vitro.

\section{ABSTRACT}

The aim of this study was to evaluate the effect of different concentrations of activated charcoal in $1 / 2$ MS (half concentration of macronutrients) culture medium under two light spectra on the in vitro growth of Cattleya loddigesii seedlings. Plantlets with approximately 90 days were subcultured under eight treatments, consisting of different active charcoal concentrations $\left(0 ; 0.5 ; 1.0\right.$ and $\left.2.0 \mathrm{~g} \mathrm{~L}^{-1}\right)$ in $1 / 2 \mathrm{MS}$ medium combined with white and red light spectra. After 180 days of germination, biometric data, fresh weight, and the level of photosynthetic pigments were evaluated. Plantlets acclimatized in a greenhouse were evaluated for survival after 120 days. Total chlorophyll, chlorophyll a, and carotenoid concentrations were higher in treatments under white light, while red light promoted greater chlorophyll $b$, plantlets with fewer and shorter roots, and high ex vitro mortality. The addition of $2.0 \mathrm{~g} \mathrm{~L}^{-1}$ of active charcoal to the culture medium and the use of white light provided greater development efficiency both on in vitro culture and ex vitro plant survival.

Key words: In vitro germination, luminosity, kinds of light, orchid, plantlets and ex vitro survival.

\section{INTRODUÇÃO}

Em razão da elevada beleza e exuberância de suas flores, as orquídeas destacam-se como importante planta ornamental e medicinal, de grande interesse econômico, ecológico e para manutenção dos ecossistemas naturais. Atualmente, seu cultivo é um comércio internacional que representa cerca de $8 \%$ do mercado mundial de plantas ornamentais e tem o potencial de alterar a paisagem econômica de um país (CHUGH et al., 2009).

IPrograma de Pós-graduação em Agronomia, Departamento de Tecnologia, Faculdade de Ciências Agrárias e Veterinárias (FCAV), Universidade Estadual Paulista (UNESP), 14884-900, Jaboticabal, SP, Brasil. E-mail: renatofgaldianojr@yahoo.com.br. Autor para correspondência.

IICurso de Agronomia, FCAV, UNESP, Jaboticabal, SP, Brasil.

IIIDepartamento de Produção Vegetal, FCAV, UNESP, Jaboticabal, SP, Brasil.

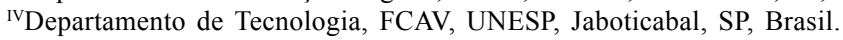


Cattleya é o gênero de Orchidaceae exclusivamente neotropical mais cultivada devido à extraordinária beleza de suas flores que a tornou popular e utilizada como matriz para híbridos (HETHERINGTON, 2002). Cattleya loddigesii apresenta bom número e tamanho das flores, sendo elas de coloração muito atrativas e duráveis (CARDOSO \& ISRAEL, 2005).

Devido à contínua destruição de seu hábitat natural, somado ao comércio e coleta ilegal, muitas espécies de orquídeas estão desaparecendo na natureza a um nível alarmante. Em decorrência, Cattleya loddigesii, espécie brasileira nativa das regiões sul e sudeste do Brasil (WATANABE \& MORIMOTO, 2007), figura na lista de espécies ameaçadas de extinção da flora do Estado de Minas Gerais (MENDONÇA \& LINS, 2000) e em risco de extinção no Estado do Rio Grande do Sul (BAPTISTA \& LONGHI-WAGNER, 1998).

O cultivo in vitro de células e tecidos constitui excelente alternativa a ser empregada para um grande número de plantas (COSTA et al., 2009). A partir da multiplicação in vitro, espécies em perigo ou consideradas em extinção podem se tornar disponíveis em quantidades de proporções comerciais e assim será possível reduzir a extração não controlada em seu habitat.

Carvão ativado é um pó finamente moído obtido a partir da combustão da madeira e, no meio nutritivo, representa uma rede muito fina de poros, com grande área de superfície e volume, o que lhe confere uma capacidade distinta de adsorção (ARDITTI \& ERNEST, 1993; THOMAS, 2008). A adição de carvão ativado ao meio nutritivo tem sido explorada para a ampliação do crescimento e desenvolvimento de células in vitro.

Assim como a composição do meio nutritivo, as condições de cultivo podem aperfeiçoar a propagação in vitro de plantas de orquídeas. Nesse aspecto, diferentes espectros de luz podem alterar o crescimento e desenvolvimento dos tecidos de plantas cultivadas in vitro (KURILCIK et al., 2008; BRAGA et al., 2009). TANAKA et al. (1998) reportaram aumento no crescimento de plântulas da orquídea terrestre Cymbidium sob luzes LED (light-emitting diodes) nas cores azul e vermelho, assim como a luz vermelha emitida por lâmpadas fluorescentes provocaram maior comprimento de broto para híbrido de Cattleya (CYBULARZ-URBAN et al., 2007) e efetividade na propagação de Odontoglossum gloriosum (PEDROZA-MANRIQUE \& MICÁN-GUTIÉRREZ, 2006). Como alternativa de baixo custo, frascos incubados em luz fluorescente branca e envolvidos por folhas de celofane vermelha foram investigados por ARAÚJO et al. (2009), tendo resultado no alongamento de plântulas de Cattleya loddigesii.
O presente trabalho teve por objetivo avaliar a propagação in vitro e aclimatização de plântulas germinadas de Cattleya loddigesii, orquídea brasileira de grande relevância ecológica e econômica, em meio nutritivo suplementado com concentrações de carvão ativado sob a luminosidade branca e vermelha.

\section{MATERIAL E MÉTODOS}

Cápsulas fechadas com sementes maduras obtidas por autopolinização artificial da espécie Cattleya loddigesii, com oito meses após a fecundação, foram superficialmente desinfestadas em etanol $70 \%$ por cinco minutos, seguido de hipoclorito de sódio com $1 \%$ de cloro ativo durante 30 minutos e enxaguadas três vezes com água destilada e autoclavada em câmara de fluxo (FARIA, 1998). Cerca de $100 \mathrm{mg}$ de sementes foram inoculadas em frascos plásticos de $220 \mathrm{~mL}$, contendo $40 \mathrm{~mL}$ de meio de cultura $1 / 2$ MS, composto pela formulação salina proposta por MURASHIGE \& SKOOG (1962), com a metade da concentração de macronutrientes e concentração total de micronutrientes, adicionado de vitaminas de MS, inositol e glicina (COSTA et al., 2009), $2 \%$ de sacarose e geleificado com $0,7 \%$ de ágar (A4675, Sigma $\left.{ }^{\circledR}\right) . \mathrm{OpH}$ do meio de cultura foi ajustado para 5,7 antes de ser autoclavado a $121^{\circ} \mathrm{C}$ e $1,1 \mathrm{~atm}$ durante 15 minutos (CALDAS et al., 1998).

A germinação e crescimento inicial ocorreram em sala de incubação sob condições controladas, com temperatura de $25 \pm 2^{\circ} \mathrm{C}$ e iluminação incidente nos frascos de, aproximadamente, $75 \mu \mathrm{mol} \mathrm{m}^{-1}$ e fotoperíodo de 16 horas luz.

Plântulas com cerca de $0,5 \mathrm{~cm}$ de altura, com a presença de dois folíolos, obtidas após 90 dias da inoculação, foram transferidas para oito diferentes tratamentos, compostos de quatro concentrações de carvão ativado $\operatorname{Sinth}^{\circledR}\left(0 ; 0,5 ; 1,0 \mathrm{e} 2,0 \mathrm{~g} \mathrm{~L}^{-1}\right)$ sob duas condições de luminosidade (luz branca fornecida por lâmpadas fluorescentes e vermelha, obtida por meio de uma folha de papel celofane vermelho envolvendo todo o frasco sob luz branca). O delineamento experimental foi num esquema fatorial $4 \times 2$, com parcelas distribuídas em forma inteiramente casualizadas e, em cada parcela, foram utilizadas 12 plântulas com cinco repetições, totalizando 480 plântulas, conforme preconizado por SOARES et al. (2008) para o maior crescimento in vitro dessa espécie. A iluminação dentro dos potes foi aferida por meio de um luxímetro (mod. MLM1010, Manipa ${ }^{\circledR}$ ). A intensidade da radiação luminosa oferecida em cada condição foi mensurada a partir de um aparelho LI 1400 dataLogger (Li-Cor, EUA), sendo constatada a radiação de $6,18 \mathrm{Wm}^{-2} \mathrm{~s}^{-1}$ e $4,86 \mathrm{Wm}^{-2} \mathrm{~s}^{-1}$ para a luz branca e 
celofane vermelho, respectivamente (médias de três repetições). A variação do comprimento de onda foi inferida envolvendo uma folha de celofane em cubeta e analisado em espectrofotômetro (UV-visível U-2000, Hitachi $^{\circledR}$, Japão), entre 240-900nm, velocidade de 200nm $\mathrm{min}^{-1}$ e resposta rápida a intervalos de $20 \mathrm{~nm}$, sendo obtida absorbância na faixa de 540nm.

Dados biométricos do número de raízes, comprimento da maior raiz, número de folhas, comprimento da maior folha, comprimento da plântula e massa fresca da plântula (parte aérea e radicular) foram coletados após 90 dias de cultivo. A quantificação dos pigmentos fotossintéticos foi a partir da extração conforme proposto por ARNON (1949) por meio da maceração de tecido foliar fresco em acetona $80 \%$. Os materiais utilizados foram até 10 plantas escolhidas aleatoriamente para cada tratamento.

Quantidades de clorofila $a$, clorofila $b$, clorofilas totais e carotenoides foram dosadas em espectrofotômetro $\left(\right.$ Beckman $^{\circledR}$, mod. DU640B) simultaneamente para as absorbâncias (A) em 662, 645, 470 e $710 \mathrm{~nm}$ e assim calculado conforme descrito por HENDRY \& PRICE, (1993): clorofila $a(11,24$ (A662$\mathrm{A} 710)-2,04(\mathrm{~A} 645-\mathrm{A} 710)$, clorofila $b=20,13(\mathrm{~A} 645-\mathrm{A} 710)-$ $4,19(\mathrm{~A} 662-\mathrm{A} 710)$, carotenoides $=(1000(\mathrm{~A} 470-\mathrm{A} 710)-$ $1,9 \mathrm{Ca}-64,13 \mathrm{Cb}) / 214$. O aparelho foi calibrado utilizando como branco acetona $80 \%$. As concentrações de pigmentos obtidas foram expressas em $\mu \mathrm{g}$ de pigmento $\mathrm{g}^{-1}$ de massa fresca.
As plântulas foram transplantadas em vasos plásticos com pó de fibra de coco e aclimatizadas em casa de vegetação com tela de nylon para retenção de $70 \%$ da intensidade luminosa e a umidade relativa mantida constante em $70 \%$. Dados de porcentagem de sobrevivência foram coletados de 50 plantas de cada tratamento após 120 dias da transferência para a aclimatização. Os dados biométricos e de pigmentos do cultivo in vitro foram transformados em $(\mathrm{x}+1)^{1 / 2}$, submetidos à análise de variância e as médias separadas pelo teste de Tukey a $5 \%$ de probabilidade por meio do programa Sisvar 4.3 (FERREIRA, 2008).

\section{RESULTADOS E DISCUSSÃO}

A maior eficiência de desenvolvimento in vitro das plântulas de Cattleya loddigesii, em todas as variáveis analisadas, foi observado com o uso do meio de cultura $1 / 2 \mathrm{MS}$ suplementado com $2,0 \mathrm{~g} \mathrm{~L}^{-1}$ de carvão ativado e sob luz branca (Tabela 1). Esta composição de meio de cultura também é recomendada para a obtenção de plântulas in vitro das espécies Cattleya walkeriana (FARIA et al., 2002), Laelia tenebrosa (ARAÚJO et al., 2006) e Sophronitis coccinea (SANTOS et al., 2006). Os efeitos promotores do carvão ativado podem ser principalmente atribuídos a sua função de retenção de substâncias tóxica presentes no meio de cultura, como, por exemplo, o 5hidroximetil-furfural, o qual é produzido a partir da

Tabela 1 - Médias biométricas de plântulas de Cattleya loddigesii cultivadas in vitro sob diferentes concentrações de carvão ativado combinados com dois espectros luminosos, após 180 dias de cultivo.

\begin{tabular}{|c|c|c|c|c|c|}
\hline \multirow{2}{*}{ Espectro de luz } & \multicolumn{4}{|c|}{ - } & \multirow{2}{*}{$\mathrm{CV}(\%)$} \\
\hline & 0 & 0,5 & 1,0 & 2,0 & \\
\hline & \multicolumn{4}{|c|}{ Número de raízes } & 9,01 \\
\hline Branca & $1,46 \mathrm{Ab}$ & $1,66 \mathrm{Aab}$ & $1,73 \mathrm{Aab}$ & $1,77 \mathrm{Aa}$ & \\
\hline \multirow[t]{2}{*}{ Vermelha } & $1,57 \mathrm{Bb}$ & $1,62 \mathrm{Bb}$ & $1,53 \mathrm{Bb}$ & $1,53 \mathrm{Bb}$ & \\
\hline & \multicolumn{4}{|c|}{ Comprimento da maior raiz $(\mathrm{cm})$} & 12,08 \\
\hline Branca & $3,17 \mathrm{Ab}$ & 3,71 Aab & $4,13 \mathrm{Aa}$ & $4,28 \mathrm{Aa}$ & \\
\hline \multirow[t]{2}{*}{ Vermelha } & $3,11 \mathrm{Bb}$ & $3,12 \mathrm{Bb}$ & $3,15 \mathrm{Bb}$ & $3,41 \mathrm{Bb}$ & \\
\hline & \multicolumn{4}{|c|}{ Número de folhas } & 21,88 \\
\hline Branca & $2,00 \mathrm{Aa}$ & $2,15 \mathrm{Aa}$ & $2,17 \mathrm{Aa}$ & $2,21 \mathrm{Aa}$ & \\
\hline \multirow[t]{2}{*}{ Vermelha } & $2,71 \mathrm{Aa}$ & $2,19 \mathrm{Aa}$ & $2,12 \mathrm{Aa}$ & $2,12 \mathrm{Aa}$ & \\
\hline & \multicolumn{4}{|c|}{ Comprimento da maior folha $(\mathrm{cm})$} & 5,86 \\
\hline Branca & $3,01 \mathrm{Ac}$ & $4,22 \mathrm{Ab}$ & $4,11 \mathrm{Ab}$ & 4,77Aa & \\
\hline \multirow[t]{2}{*}{ Vermelha } & $3,48 \mathrm{Ac}$ & $4,48 \mathrm{Ab}$ & $4,50 \mathrm{Ab}$ & $3,64 \mathrm{Ac}$ & \\
\hline & \multicolumn{4}{|c|}{ Massa fresca da plântula (g) } & 13,58 \\
\hline Branca & $5,26 \mathrm{Bc}$ & $8,51 \mathrm{Ab}$ & $9,98 \mathrm{Aab}$ & $10,84 \mathrm{Aa}$ & \\
\hline Vermelha & $6,6 \mathrm{Bc}$ & $7,9 \mathrm{Bc}$ & $8,11 \mathrm{Bc}$ & $8,2 \mathrm{Bc}$ & \\
\hline
\end{tabular}

Letras maiúsculas correspondem ao espectro de luz e minúsculas a concentrações de carvão ativado. Médias não seguidas pela mesma letra diferem estatisticamente entre si pelo teste de Tukey $(5 \%)$. 
desidratação da sacarose durante a autoclavagem, ou substâncias inibitórias presentes no ágar ou também para reduzir a ação de metabólitos tóxicos, tais como substâncias fenólicas, etileno e ácido abscísico que são eliminados pelo explante (PAN \& STADEN, 1998; THOMAS, 2008).

Concentrações elevadas $\left(1,0\right.$ e $\left.2,0 \mathrm{~g} \mathrm{~L}^{-1}\right)$ de carvão ativado sob luz branca favoreceram o enraizamento in vitro de Cattleya loddigesii (Tabela 1). Resultado similar também foi verificado por LÉDO et al. (2007) para o crescimento inicial de mangabeira (Hancornia speciosa), em que a adição de carvão ativado ao meio induziu maior crescimento da raiz principal. Este efeito pode ser atribuído à promoção de maior aeração do meio nutritivo e evitação da luz para as raízes (ARDITTI \& ERNEST, 1993), propiciando assim condições mais adequadas no local do crescimento radicular. No presente trabalho, observouse que a utilização da luz vermelha proporcionou uma redução do crescimento da maior raiz, quando comparado com o uso da luz branca (Tabela 1). Resposta semelhante também foi observado por ARAÚJO et al. (2009) para esta mesma espécie de orquídea. Outro fator relevante, observado no presente estudo, foi que a luz vermelha obtida pela folha de celofane apresenta intensidade luminosa menor (600lux) dentro dos potes, quando comparado com a luz das lâmpadas brancas (1000lux). Característica que provavelmente reduziu a função do carvão ativado no meio nutritivo, uma vez que o menor fornecimento de energia luminosa pode implicar redução do crescimento da plântula.

A massa fresca das plantas de Cattleya loddigesii foi superior em luz branca com $2,0 \mathrm{~g} \mathrm{~L}^{-1}$ de carvão ativado. Para a aquisição de biomassa, a luz vermelha foi ineficiente, mesmo com a adição de carvão ativado, o que reforça o fato de que a limitação do espectro oferecida pela luz vermelha trouxe atraso tanto para o crescimento radicular quanto para a aquisição de biomassa in vitro.

As quantidades de pigmentos fotossintéticos apresentaram variações entre os tratamentos utilizados (Tabela 2). Houve diferenças significativas entre os tipos de luminosidade, em que a luz branca proporcionou a maior produção de clorofila $a$, clorofila total, carotenoides e relação clorofila $a / b$. De maneira distinta, na luz vermelha, foi registrada a maior produção de clorofila $b$.

A maior produção de clorofila $b$ pode estar associada à resposta das plântulas in vitro diante das condições luminosas mais limitantes. MARTINS et al. (2010) verificaram maior biossíntese de clorofila $b$ em plantas de alfavaca-cravo (Ocimum gratissimum), cultivadas em casa de vegetação sob malha preta com retenção de $50 \%$ da luminosidade. Esse resultado corrobora a menor intensidade luminosa oferecida sob luz vermelha mensurada pelo luxímetro.

Tabela 2 - Teores médios de pigmentos fotossintéticos de plântulas de Cattleya loddigesii cultivadas in vitro sob diferentes concentrações de carvão ativado combinados com dois espectros de luminosidade, após 180 dias de cultivo.

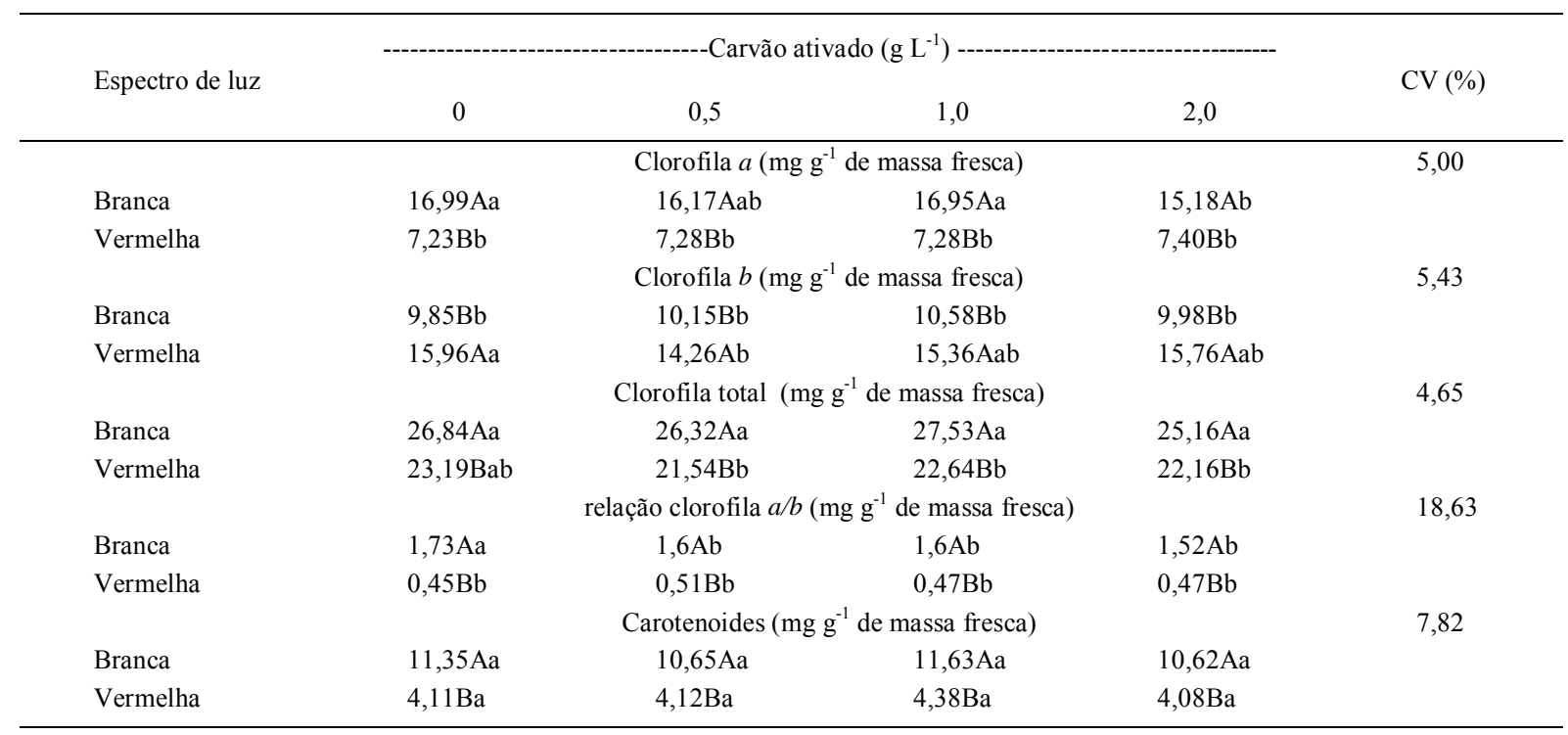

Letras maiúsculas correspondem ao espectro de luz e minúsculas a concentrações de carvão ativado. Médias não seguidas pela mesma letra diferem estatisticamente entre si pelo teste de Tukey $(5 \%)$.

Ciência Rural, v.42, n.5, mai, 2012. 
A relação clorofila $a / b$ apresentada nos tratamentos sob luz vermelha foram talvez menores que as verificadas em plantas sob luz branca, devido à discrepância observada entre os elevados teores de clorofila $b$ e o inverso em relação à clorofila $a$ para estes tratamentos. A função da clorofila $b$ é referente à absorção de energia luminosa em comprimentos de ondas distintos da clorofila a que amplia, consequentemente, a quantidade de fótons para o centro de reação da atividade fotossintética (TAIZ \& ZEIGER, 2006).

Outra variação observada foram os teores de carotenoides, significativamente maiores na luz branca. Esses pigmentos desempenham função essencial como fotoprotetores (TAIZ \& ZEIGER, 2006). Dessa maneira, a menor produção de carotenoides representa um ajustamento fisiológico de plântulas de Cattleya loddigesii ao espectro vermelho.

Para a aclimatização e sobrevivência ex vitro, esta condição de incubação foi desfavorável (Figura 1). A maior quantidade de raízes é essencial e deve ser estimulada para maior sobrevivência durante a aclimatização de orquídeas (SORACE et al., 2007; COSTA et al., 2009).

Plântulas que foram cultivadas in vitro sob luz vermelha apresentaram maior índice de mortalidade durante a aclimatização (Figura 1). Este evento pode estar relacionado à menor quantidade de raízes, menor teor e um desbalanço do tipo de clorofilas produzido pelas plântulas, quanto cultivadas no espectro de luminosidade de cor vermelha.

\section{CONCLUSÃO}

Plântulas cultivadas sob luz vermelha, mesmo nas concentrações mais elevadas de carvão ativado, resultaram em menor produção de massa de matéria fresca, menor mudança da quantidade de pigmentos fotossintéticos das plântulas in vitro e menor sobrevivência em casa de vegetação. Enquanto que a adição de $2,0 \mathrm{~g} \mathrm{~L}^{-1}$ de carvão ativado no meio nutritivo sob luz branca favoreceu maior crescimento in vitro e maior porcentagem de sobrevivência ex vitro de plantas de Cattleya loddigesii e é, portanto, a combinação de tratamentos recomendável para a propagação dessa espécie nativa.

\section{AGRADECIMENTOS}

Os autores agradecem ao CNPq, à CAPES e à FAPESP pelo suporte financeiro. À Profa. Dra. Lúcia Maria Carareto Alves, do Departamento de Tecnologia da FCAVUNESP, pelo auxílio na interpretação do espectro de absorbância luminosa.

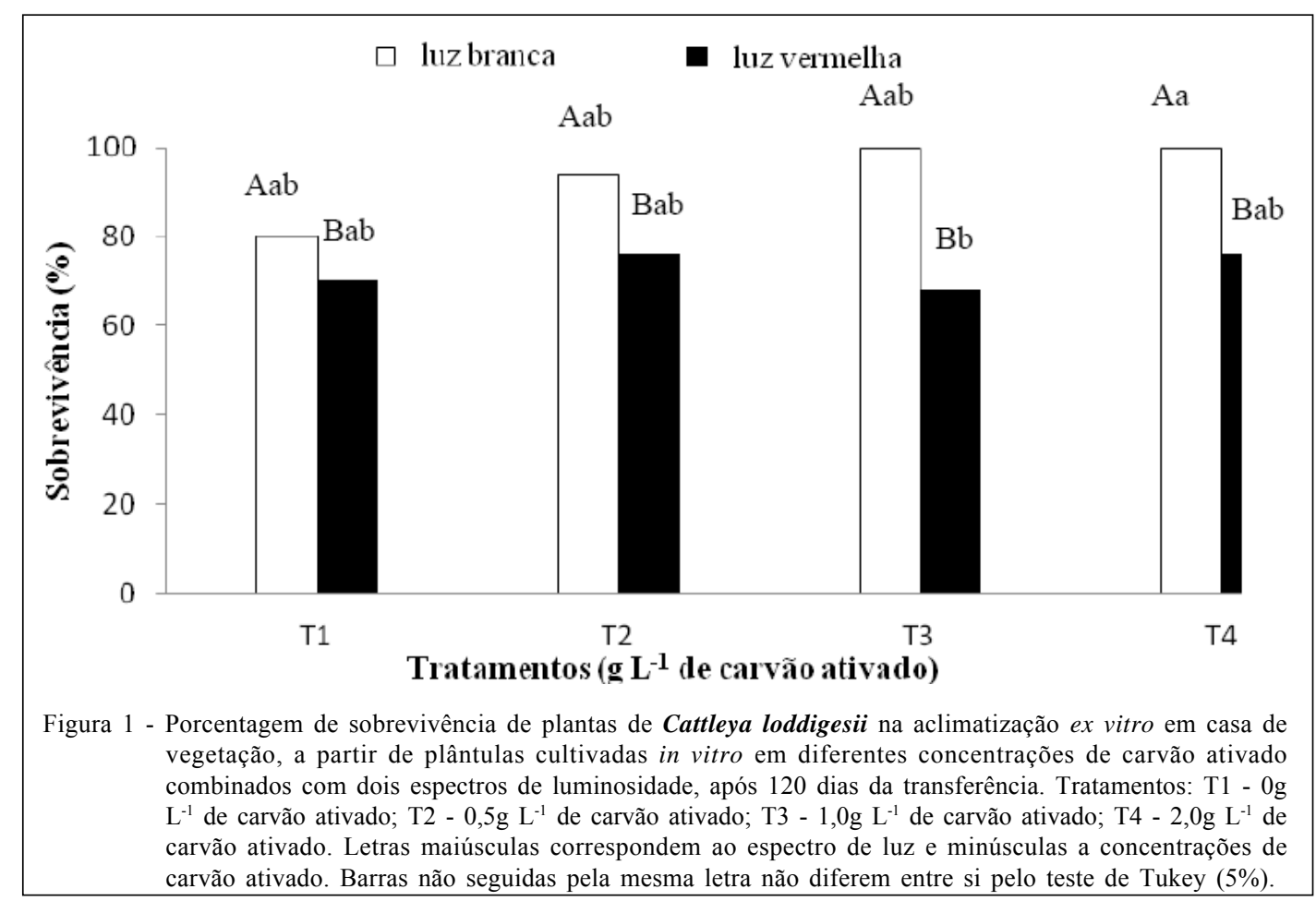

Ciência Rural, v.42, n.5, mai, 2012. 


\section{REFERÊNCIAS}

ARAÚJO, A.G. et al. Crescimento in vitro de Laelia tenebrosa (Orchidaceae) em diferentes concentrações de sais de Knudson-C e carvão ativado. Plant Cell Culture and Micropropagation, v.2, n.2, p.61-67, 2006. Disponível em: <http://www.abctp.ufla.br/ v2n2.pdf $>$. Acesso em: 15 jun. 2011.

ARAÚJO, A.G. et al. Crescimento in vitro de Cattleya loddigesii Lindl. em diferentes espectros luminosos associados com ácido giberélico. Ceres, v.56, n.5, p.542-546, 2009. Disponível em: $<$ http://www.ceres.ufv.br/ceres/revistas/V56N005P07807.pdf>. Acesso em: 12 nov. 2010.

ARDITTI, J.; ERNST, R. Micropropagation of orchids. New York: J. Wiley, 1993. 682p.

ARNON, D.I. Copper enzymes in isolated chloroplasts: polyphenoloxydase in Beta vulgaris. Plant Physiology, v.24, n.1, p.1-15, 1949. Disponível em: <http://www.plantphysiol.org/ content/24/1/1.full.pdf + html $>$. Acesso em: 23 jan 2012. doi: http://dx.doi.org/10.1104/pp.24.1.1

BAPTISTA, L.R.M.; LONGHI-WAGNER, H.M. (Coord.). Lista preliminar de espécies ameaçadas da flora do Rio Grande do Sul. Porto Alegre. Sociedade de Botânica do Brasil, 1998. 72p.

BRAGA, F.T. et al. Qualidade de luz no cultivo in vitro de Dendranthema grandiflorum cv. Rage: características morfofisiológicas. Ciência e Agrotecnologia, v.33, n.2, p.502-508, 2009. Disponível em: http://www.scielo.br/pdf/ cagro/v33n2/v33n2a22.pdf. Acesso em: 17 out. 2010. doi: 10.1590/S1413-70542009000200022.

CALDAS, L.S. et al. Cultura de tecidos e transformação genética de plantas. Brasília: Embrapa CENARGEN, 1998. V.1, p. 87-132.

CARDOSO, J.C.: ISRAEL, M. Levantamento de espécies da família Orchidaceae em Águas de Sta. Bárbara (SP) e seu cultivo. Horticultura Brasileira, v.23, n.2, p.169-173, 2005. Disponível em: <http://www.scielo.br/pdf/hb/v23n2/25046.pdf $>$. Acesso em: 20 out. 2010. doi: 10.1590/S010205362005000200001 .

CYBULARZ-URBAN, T. et al. Effect of light wavelength on in vitro organogenesis of a Cattleya hybrid. Acta Biologica Cracoviensia, v.49, n.1, p.113-118, 2007. Disponível em: $<$ http://www.ib.uj.edu.pl/abc/pdf/49_1/14cybula.pdf $>$. Acesso em: 22 out. 2011.

CHUGH, S. et al. Micropropagation of orchid: a review on the potential of different explants. Scientia Horticulture, v.122, n.4, p.507-520, 2009. Disponível em: <http://pdn.sciencedirect.com/ science?_ob=MiamiImage URL\&_cid=271177\& _user $=2139813 \&$ \& pii $=$ S 0304423809003641 \&_check $=y$ 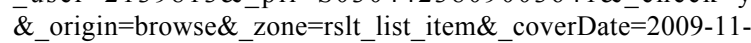 03\&wchp=dGLbVBA-zSkWz\&md5=9503e220ffc97e5be0ff21c32a355ede/ 1-s2.0-S0304423809003641-main.pdf`. Acesso em: 23 jan. 2012. doi:10.1016/j.scienta.2009.07.016.

COSTA, M.A.P.C. et al. Micropropagação de orquídeas. In: JUNGHANS, T.G.; SOUZA, A.S. Aspectos práticos da micropropagação de plantas. Cruz das Almas: EMBRAPA MFT, 2009. V.1, p.351-370.
FARIA, R.T. Micropropagação de Dendrobium nobile in vitro. In: TOMBOLATO, A.F.C.; COSTA, A.M.M. Micropropagação de plantas ornamentais. Campinas: Instituto Agronômico, 1998. p.63-67.

FARIA, R.T. et al. Preservation of the Brazilian orchid Cattleya walkeriana Gardner using in vitro propagation. Crop Breeding and Applied Biotechnology, v.2, n.3, p.489-492, 2002.

FERREIRA, D.F. SISVAR: um programa para análises e ensino de estatística. Revista Symposium, v.6, n.1, p.36-41, 2008. Disponível em: <http://www.fadminas.org.br/symposium/ 12_edicoes/artigo_5.pdf>. Acesso em: 5 out. 2010.

HENDRY, G.A.F.; PRICE, A.H. Stress indicators: chrorophylls and carotenoids. In: HENDRY, G.A.F.; GRIME, J.P. Methods in comparative plant ecology. London: Chapman \& Hall, 1993. p.150-152.

HETHERINGTON, E. Influência de Cattleya labiata na hibridação. In: MENEZES, L.C. Cattleya labiata autumnalis. Brasília: IBAMA, 2002. p.235-247.

KURILCIK, A. et al. In vitro culture of Chrysanthemum plantlets using light-emitting diodes. Central European Journal of Biology, v.3, n.2, p.161-167, 2008. Disponível em: <http:// www.springerlink.com/content $/ 218513 \mathrm{~h} 2541 \mathrm{j} 6541 /$ fulltext.pdf $>$. Acesso em: 22 out. 2011. doi: 10.2478/s11535008-0006-9.

LÉDO, A.S. et al. Crescimento inicial de mangabeira (Hancornia speciosa Gomes) em diferentes meios de germinação in vitro. Ciência e Agrotecnologia, v.31, n.4, p.989-993, 2007. Disponível em: $<$ http://www.scielo.br/pdf/cagro/v31n4/07.pdf>. Acesso em: 17 out. 2010. doi: $10.1590 /$ S1413-70542007000400007.

MARTINS, J.R. et al. Teores de pigmentos fotossintéticos e estrutura de cloroplastos de Alfavaca-cravo cultivadas sob malhas coloridas. Ciência Rural, v.40, n.1, p.64-69, 2010. Disponível em: <http://www.scielo.br/pdf/cr/v40n1/a412cr1385.pdf >. Acesso em: 25 maio, 2011. doi: 10.1590/S0103-84782010000100011.

MENDONÇA, M.P.; LINS, L.V. Lista vermelha das espécies ameaçadas de extinção da flora de Minas Gerais. Belo Horizonte: Fundação Biodivérsitas, 2000. 157p.

MURASHIGE, T.; SKOOG, F. A revised medium for a rapid growth and biossays with tabacco tissue cultures. Physiologia Plantarum, v.15, n.3, p.473-497, 1962.

PAN, M.J.; STADEN, J.V. The use of charcoal in in vitro culture - a review. Plant Growth Regulation, v.26, p.155163, 1998.

PEDROZA-MANRIQUE, J.; MICÁN-GUTIÉRREZ, Y. Asymbiotic germination of Odontoglossum gloriosum Rchb.F. (Orchidaceae) under in vitro conditions. In Vitro Cell and Developmental Biology-Plant, v.42, p.543-547, 2006. Disponível em: <http://www.springerlink.com/content/ b02636144078544v/fulltext.pdf $>$. Acesso em: 23 out. 2011. doi: $10.1079 /$ IVP2006793.

SANTOS, A.F. et al. Otimização da propagação de Sophronitis coccinea (Orchidaceae) considerando meios de cultivo com adição de carvão ativado. Horta, v.46, p.8-12, 2006. 
SOARES, J.D.R. et al. Crescimento in vitro de orquídeas: quantidade de meio e número de explantes. Ceres, v.55, n.1, p.49-53, 2008. Disponível em: <http://www.ceres.ufv.br/ceres/ revistas/V55N001P00808.pdf>. Acesso em: 10 nov. 2010.

SORACE, M. et al. Influência de auxina na aclimatização de Oncidium baueri (Orchidaceae). Semina, v.28, n.2, p.195200, 2007. Disponível em: <http://www.uel.br/revistas/uel/ index.php/semagrarias//article/view/3427/2786>. Acesso em: 8 jun. 2011

TANAKA, M. et al. In vitro growth of Cymbidium plantlets cultured under super bright red and blue light-emitting diodes. Journal of Horticultural Science and Biotechnology, v.73, p.39-44, 1998 .
TAIZ, L.; ZEIGER, E. Fisiologia vegetal. 4.ed. Porto Alegre: Artmed, 2006. 819p.

THOMAS, T.D. The role of activated charcoal in plant tissue culture. Biotechnology Advances, v.26, p.618-631, 2008. Disponível em: $<$ http:/ /pdn.sciencedirect.com/science?_ob=MiamiImageURL\&_cid=27133 $6 \&$ _ u s e r $=2139813 \&$ \& p i i $=$ S 07349750 $08000864 \& \quad \mathrm{check}=\mathrm{y} \&$ origin $=$ artic le $\&$ $\mathrm{z}$ o n e $=$ t o o $1 \overline{\mathrm{b}}$ a r \& $\&_{-} \mathrm{cov}$ e r D a t e $=31-\mathrm{D}$ e c $2008 \&$ view $=$ c\&originContentFamily $=$ serial\&wchp $=\mathrm{dGLzVlk}$ zSkWA\&md5=6611 a3edaf2d08be39121 c7e38aa4d01/1-s2.0 S0734975008000864-main.pdf $>$. Acesso em: 23 jan. 2012. doi: 10.1016/ j.biotechadv.2008.08.003.

WATANABE, D.; MORIMOTO, M.S. Orquídeas: manual de cultivo. São Paulo: AOSP, 2007. 347p. 